\section{Tachistoscopic recognition of geometric forms by children and adults}

MARSHALL $M$. HAITH, FREDERICK $J$. reported disturbingly large within-age and MORRISON, and KAREN SHEINGOLD, between-age variability for the exposure Harvard University, Cambridge, Mass. time necessary to reach $50 \%$ recognition 02138

Preschool children and college adults were presented pictures of simple outlined geometric forms at tachistoscopic exposure durations of $5,10,20,30$, and 40 msec. When accuracy was plotted as a function of exposure duration, the curve of 5-year-olds approximated that of adults. However, 5-year-olds reached given performance levels at exposure durations that were $5-10$ msec longer than those of adults. The age differences, considered to be relatively minor, were discussed in terms of faster visual processing time and better usage of partial cues by adults. It was concluded that the use of stimulus durations that do not permit eye movements is feasible in studies of preschool Ss. Thus, hypotheses about the development of visual operations in information processing can be tested without confounding the influence of age differences in visual scanning.

Recent experiments have attempted to isolate and study the internal operations that occur in the perception and storage of a briefly presented stimulus (Averbach \& Coriell, 1961; Neisser, 1967; Sperling, $1960,1967)$. Knowledge about the nature of these operations-short-term visual storage and stimulus encoding, to name two-has contributed to information-processing models of visual perception and memory (Haber, 1966). Although these processes have been investigated almost exclusively in the adult, developmental studies of visual information flow might yield more exact specifications of how childhood perception and memory change to assume their adult form.

Investigation of visual processing operations often requires precise control over the visual information that is available to the S. Such control has been readily accomplished by using a tachistoscope (T-scope) to present stimuli at exposure durations that prohibit eye movements. $T$-scope procedures seem especially necessary for developmental studies in order to eliminate the effects of age-related differences in eye-movement strategies (Mackworth \& Bruner, 1966; Vurpillot, 1968; Zinchenko \& Ruzskaya, 1965).

Only a few T-scope studies on preschoolers have been done. These have

\section{EQUIPMENT AND MATERIALS}

A Gerbrands three-field mirror tachistoscope was used in conjunction with two solid-state timers that were adjustable from $10 \mathrm{msec}$ to $1 \mathrm{sec}$ in 10-msec steps (2\% accuracy). Each stimulus field was illuminated by two 4-W fluorescent tubes viewed through two Liberty 30-30 mirrors (Libbey-Owens-Ford Glass, Spec. No. 1064). A button, mounted in a hand-held box, served to activate a timer sequence resulting in stimulus exposure for a fixed duration.

The stimuli were 10 outlined geometric forms (Fig. 1), each positioned at the center of a white bristol-board card (Staedtler Pen, Mars-700, Tip 700 05). Each stimulus item subtended $33 \mathrm{~min}$ of visual angle with a line thickness of $2 \mathrm{~mm}$ at the subject-field distance of $32 \mathrm{in.} \mathrm{The}$ field of the tachistoscope was $7 \frac{1}{4} \times 7 \frac{1}{4} \mathrm{in}$. permitting the $S$ to see a white 12.75-deg square field. The illumination of the stimulus field, integrated over a $\pm 1 \frac{112-d e g}{}$ visual angle of center, was an average of $1.91 \mathrm{fL}$. The illumination of a fixation field containing a tiny centered dot was $1.92 \mathrm{fL}$.

A response card, mounted on the right side of the T-scope viewing mask, displayed the whole set of 10 forms (Fig. 1), identical in size to those on the stimulus card.

\section{PROCEDURE}

At the beginning of a trial, the fixation field was illuminated. The $S$ fixated the dot and pressed the button. After a 750-msec delay, the fixation field went off followed by illumination of the stimulus field (variable duration) and then illumination of the fixation field. There was no interfield interval. $S$ indicated which stimulus he thought he saw by pointing to one of the forms on the response card. Throughout the experiment, Ss were repeatedly encouraged to look at the fixation dot before pressing the button. The Ss differed somewhat in their T-scope experience. Twelve adults and 12 5-year-olds had served in a short-term memory experiment (STM condition). The remaining Ss (nine 4-year-olds, three 5 -year-olds, and six adults) received 10 trials ( $\mathrm{T}$ condition) immediately before the present experiment in which single stimuli were presented either for a fixed duration of $40 \mathrm{msec}$ or for a variable duration between 40 and $80 \mathrm{msec}$. Recognition accuracy did not vary systematically as a function of any of these preexperimental conditions. However, the recognition accuracy of T-condition Ss at the 40-msec duration is reported as an additional data point in the results section. In the experimental phase, with the exception of six adults, each $S$ received 30 trials consisting of the 10 stimuli presented for

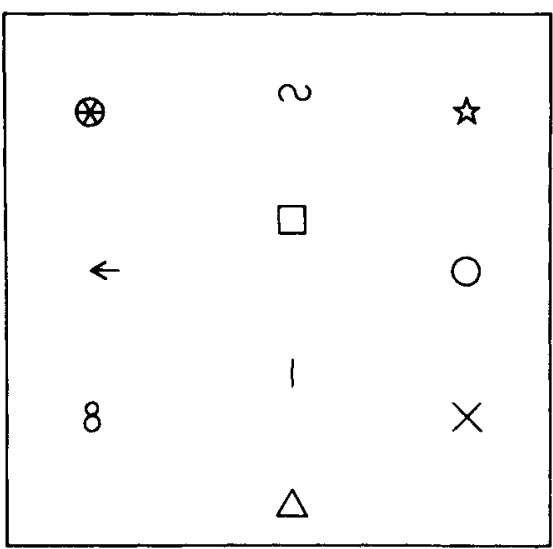

Fig. 1. Response card that displayed all of the possible stimuli. 
Fig. 2. Recognition accuracy as a function of exposure duration for 4-year-olds, 5-year-olds, and adults (averaged over experience groups). The numbers in parentheses indicate the number of Ss at each point (corrected for guessing).

10,20 , and $30 \mathrm{msec}$ in a random order with the restrictions that no exposure duration occur twice in succession, that an equal number of the three durations appear in each block of 15 trials, and that each stimulus appear once in a block of 10 trials. Because preliminary findings suggested that adults, but not children, were above $50 \%$ recognition accuracy at $10 \mathrm{msec}$, the $\mathrm{T}$-scope timers were modified and six adult Ss were presented the stimuli for 5,10 , and $20 \mathrm{msec}$ to assess their $50 \%$ threshold.

\section{RESULTS}

The mean percent correct as a function of age and exposure duration is shown in Fig. 2 (averaged over the experience subgroups). ${ }^{2}$ Performance at the 40 -msec duration is shown for the relevant $T$ condition Ss with the number of Ss at each point in parentheses. It can be seen that the mean adult performance was below $50 \%$ accuracy at $5 \mathrm{msec}$, but above $50 \%$ accuracy at 10, 20, and $30 \mathrm{msec}$. The performance of the 5-year-old children closely approximated that of adults at 20 and $30 \mathrm{msec}$ but was depressed at the 10-msec duration. Inspection of the overall shape of the 5-year-old children's curve indicates that their performance approximately matched that of the adults but with about a 5-10 msec lag. Performance for the 4-year-olds was somewhat below that of the adults and the 5 -year-olds at 20 and $30 \mathrm{msec}$, but well above $50 \%$. However, as with the 5-year-olds, performance was depressed at $10 \mathrm{msec}$. The average values represent stable within-group performance. All children were at $(\mathrm{N}=3)$ or above $(\mathrm{N}=20)$ $50 \%$ accuracy at the $20-\mathrm{msec}$ exposure duration. At the $10-\mathrm{msec}$ duration, one child was above $50 \%, 3 \mathrm{Ss}$ were at $50 \%$, and 19 Ss were below 50\% accuracy. All adults were above $50 \%$ accuracy at $10 \mathrm{msec}$. At $5 \mathrm{msec}$, all but one adult were below $50 \%$ accuracy.

\section{DISCUSSION}

Clearly, orderly performance can be obtained from preschool children when simple outlined geometric forms are presented at subscan durations. The most surprising finding of the present study, in our opinion, was that the additional time required by preschoolers to reach adult performance levels was so slight. The criterion of $50 \%$ recognition accuracy was, with one exception, reached by every 4 .

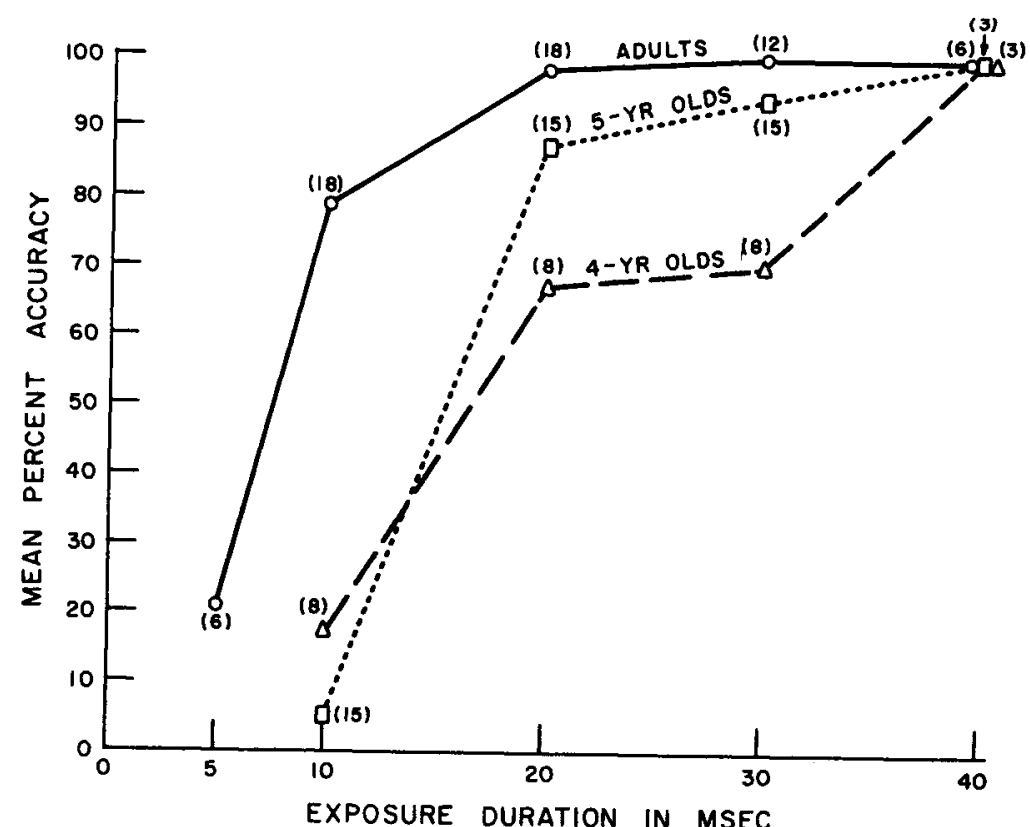

and 5-year-old in the 10 to $20-\mathrm{msec}$ accuracy reflected a true difference in stimulus-duration range. In general, the visual processing rate, i.e., it may be that children's accuracy at the very brief the perceptual image is constructed more exposure durations used in this study was slowly by the child. Alternatively, the encouraging. It should be noted that the visual image, which outlasts the actual stimulus parameters of the present study stimulus exposure (Sperling, 1960), might did not maximize the contrast between persist longer for adults than for children stimulus and field. That is, the stimuli were effectively giving the adults more visual drawn with thin lines, the field processing time. This last interpretation is illumination was somewhat dim, and the being tested in a study of developmental illumination during the prestimulus, changes in processing time under stimulus, and poststimulus intervals was backward masking conditions. Finally, it is held constant. Optimization of any of possible that the use of random these parameters could further increase presentation of stimulus durations was recognition accuracy. However, since the more disruptive to the child's performance. reaction time for an eye movement is around $250 \mathrm{msec}$, it is clear that preschoolers can function well, even under the present conditions, in visual experiments that do not permit scanning of the stimulus; thus, future developmental studies need not confound age-related eye-movement strategies with the internal processing of stimulus input.

Although the general impression of the curves shown in Fig. 2 is one of substantial similarity among groups in performance, the age differences in accuracy at the 10 -msec exposure duration is worthy of comment. It is possible that only part-forms were perceived by all $S$ at the 10-msec duration (supported by reports from some adult $\mathrm{Ss}$ ) and that adults were better able to make the inferential cognitive steps leading to a correct response. For example, given the appropriate logical strategy, the detection of one 90 -deg angle in a brief flash would be sufficient information for $S$ to make a correct "square" response. However, it is also possible that the difference in
Studies are currently under way in which exposure time decreases systematically.

The findings of the present study stand in sharp contrast to those of earlier studies both in terms of average performance and in the range of performance of preschoolers. Ghent (1960) presented pictures of objects (approximately $32 \mathrm{~min}$ in visual angle) to children and found a median $50 \%$ recognition accuracy at exposure durations of 20 and $5 \mathrm{msec}$ for 4 and 5-year-olds, respectively, with ranges of $10-200 \mathrm{msec}$ and $5-40 \mathrm{msec}$. Similar results were reported by Ghent \& Bernstein (1961) (stimuli subtending $2.8 \mathrm{deg}$ of visual angle) with medians for 4- and 5-year-olds of 20 and $5 \mathrm{msec}$, respectively, with ranges of $3-100 \mathrm{msec}$ and $3-20 \mathrm{msec}$. A clear report of how these medians were obtained was not given. Munsinger (1965) presented solid "nonsense" forms (visual angle of $43 \mathrm{~min}$ ) to 4 - and 5-year-olds and college adults. A range of $40 \%-95 \%$ accuracy was found for children at exposure durations between 80 and $400 \mathrm{msec}$ and for adults, between 5 and 
$18 \mathrm{msec}$. Although a variety of visual parameters can affect the absolute duration at which $50 \%$ recognition occurs, it is not obvious why such differences between the present study and previous studies would affect within-age and between-age variability. (In fairness, it should be noted that it was not the primary purpose of earlier studies to establish time and recognition-accuracy relationships.) It is quite possible that the recognition values in the Ghent (1960), Ghent \& Bernstein (1961), and Munsinger (1965) studies, because of the nature of the tasks and of the visually more complex materials they employed, reflected primarily cognitive differences (such as the relative degree of sophistication used in inferring the stimuli from partial cues) between Ss, whereas the present findings primarily reflected perceptual differences.

\section{REFERENCES}

AVERBACH, E., \& CORIELL, A. I., Short-term memory in vision. Bell System Technical Journal, 1961, 309-328.

GHENT, L. Recognition by children of realistic figures presented in various orientations. Canadian Journal of Psychology, 1960, 14, 249-256.

GHENT, L., \& BERNSTEIN, L. Influence of the orientation of geometric forms on their recognition by children. Perceptual \& Motor Skills, 1961, 12, 95-101.

HABER, R. N. Perception and thought: An information processing analysis. Paper presented at the conference on "Approaches to Thought," sponsored by The Learning Research and Development Center, at the University of Pittsburgh, October 13 and 14, 1966.

MACKWORTH, N., \& BRUNER, J. S. Selecting visual information during recognition by adults and children. Unpublished paper, Center for Cognitive Studies, Harvard University, 1966.

MUNSINGER, H. Tachistoscopic recognition of stimulus variability. Journal of Experimental Child Psychology, 1965, 2, 186-191.

NEISSER, U. Cognitive psychology. New York: Appleton-Century-Crofts, 1967.

SPERLING, $G$. The information available in brief visual presentations. Psychological Monographs, 1960, 75, Whole No. 498, 1-29.

SPERLING, G. Successive approximations to a model for short-term memory. In Eighteenth International Congress of Psychology, Symposium 22, Memory and action. Amsterdam: North Holland Publishing, 1967.

VURPILLOT, E. JuGging visual similarity: The development of scanning strategies. Unpublished paper, Center for Cognitive Studies, Harvard University, 1966.

ZINCHENKO, V. P., \& RUZSKAYA, A. G Reported in A. V. Zaporozhets, The development of perception in the preschool child. In P. H. Mussen (Ed.), European research in cognitive development. Monograph, Social Kesearch \& Child Development, 1965 , 30, 82-101.

\section{NOTES}

1. The present investigation and the analys1s and preparation of this paper were supported by U.S. Public Health Grant HD 02680 to the senior author. Miss Paula Mindes assisted in the collection and analysis of the data. Special gratitude is owed Mrs. Harrington and Mrs. Mitchell and the Green Acres School in Waltham, Massachusetts, for supplying the children and space needed for the present study. We would also like to thank the Boston community mothers who made their children available for study at Harvard University. The authors acknowledge the helpful suggestions of Rochelle Gelman, John Belmont, Earl Butterfield, and Ralph Haber.

2. The mean accuracy scores were corrected for chance guessing by subtracting $1 / 10\left(1-P_{\text {observed }}\right)$ from the raw mean score.

\section{Effects of knowledge of results on schematic concept formation with linguaform patterns ${ }^{1}$}

\section{JANE M. GLASGOW and ELVIS C. JONES ${ }^{2}$, Augusta College, Augusta, Ga. 30904}

It was reported, in an earlier study, that knowledge of results (KR) did not aid learning in an oddity task with linguaform patterns. In the present study $K R$ was found to aid learning. In fact, performance was not significantly above chance when $K R$ was not provided. It was concluded that further analysis of the role of $K R$ in schema learning tasks is badly needed.

The findings of studies comparing the effects of knowledge of results (KR) and no knowledge of results (NKR) on schema learning tasks have been inconsistent. Some have found KR to have no effect (e.g., Hollier \& Evans, 1967), some have found it to have a negative effect (e.g., Brown, Walker, \& Evans, 1968). Still others have found KR to have a positive effect (e.g., Pearre \& Jones, 1968).

Hollier \& Evans (1967), employing computer-generated linguaforms in an oddity task, found no significant differences between Ss provided with KR or NKR. The present study represents an attempt to replicate the essential features of their study. In the present case, however, it was hypothesized that KR would facilitate performance.

\section{METHOD}

The Ss were 20 experimentally naive students enrolled in an introductory psychology course. They were randomly assigned to two groups of $10 \mathrm{Ss}$.

The linguaforms were constructed in the same manner as those employed by Hollier \& Evans (1967) except that the odd sentences were always $0 \%$ redundant. A total of 20 sets of three sentences were used. The experimental procedure differed from that of Hollier and Evans only in the following ways: $K R$ was provided the $K R$ group by a sheet following each set of sentences upon which the number of the odd sentence was printed; the booklets used by the NKR group were identical except the page was blank. The Ss were given $30 \mathrm{sec}$ in which to mark their answers and to look at the KR page (or the blank page). Blackened sheets were inserted behind each set of sentences to prevent Ss from viewing the KR sheets, and Ss were not allowed to turn to previous pages in the booklets. The most probable sequence was PA, HA, RO, GE, KO, ME, LA.

RESULTS AND DISCUSSION

The data indicated that the KR group's performance was superior to that of the NKR group. The mean number of correct responses was 10.5 for the KR group and 7.5 for the NKR group. This difference was statistically significant $(t=1.77, d f=18$, $p<.05)$ and in the predicted direction. Moreover, the NKR group failed to perform significantly better than chance $(p>10)$, whereas the KR group did $(p<.05)$. The results indicate that KR does have a positive effect on the present task. However, the effects do not appear to be very powerful.

Pearre \& Jones (1968) have briefly summarized some factors that may determine the effectiveness of $\mathrm{KR}$ in some schema tasks. However, much more consideration must be given to this problem. In general, the trend of research suggests that $K R$ aids in the learning of schemata, although KR may not be necessary in order for schema learning to occur.

\section{REFERENCES}

HOLLIER, J., \& EVANS, S. H. Schematic concept formation with linguaform patterns. Psychonomic Science, 1967, 9, 89-90.

BROWN, B. R., WALKER, D. W., \& EVANS, S. $\mathrm{H}$. Schematic concept formation as a function of constraint redundancy and knowledge of results. Psychonomic Science, 1968, 11, 75-76. PEARRE, J. G., \& JONES, E. C. Effects of knowledge of results on schematic concept formation. Psychonomic Science, 1968, 12, 367-368.

\section{NOTES}

1. This research was conducted as an undergraduate research project by the first author and sponsored by the second author.

2. Now at Frostburg State College, Frostburg, Maryland. 